\title{
Quercetin inhibits HGF/c-Met signaling and HGF- stimulated melanoma cell migration and invasion
}

\author{
Hui-Hui Cao, Chi-Yan Cheng, Tao Su, Xiu-Qiong Fu, Hui Guo, Ting Li, Anfernee Kai-Wing Tse, Hiu-Yee Kwan, \\ Hua Yu and Zhi-Ling Yu*
}

\begin{abstract}
Background: Melanoma is notorious for its propensity to metastasize, which makes treatment extremely difficult. Receptor tyrosine kinase c-Met is activated in human melanoma and is involved in melanoma progression and metastasis. Hepatocyte growth factor (HGF)-mediated activation of c-Met signaling has been suggested as a therapeutic target for melanoma metastasis. Quercetin is a dietary flavonoid that exerts anti-metastatic effect in various types of cancer including melanoma. In a previous report, we demonstrated that quercetin inhibited melanoma cell migration and invasion in vitro, and prevented melanoma cell lung metastasis in vivo. In this study, we sought to determine the involvement of HGF/c-Met signaling in the anti-metastatic action of quercetin in melanoma.
\end{abstract}

Methods: Transwell chamber assay was conducted to determine the cell migratory and invasive abilities. Western blotting was performed to determine the expression levels and activities of c-Met and its downstream molecules. And immunoblotting was performed in $\mathrm{BS}^{3}$ cross-linked cells to examine the homo-dimerization of c-Met. Quantitative real-time PCR analysis was carried out to evaluate the mRNA expression level of HGF. Transient transfection was used to overexpress PAK or FAK in cell models. Student's t-test was used in analyzing differences between two groups.

Results: Quercetin dose-dependently suppressed HGF-stimulated melanoma cell migration and invasion. Further study indicated that quercetin inhibited c-Met phosphorylation, reduced c-Met homo-dimerization and decreased c-Met protein expression. The effect of quercetin on c-Met expression was associated with a reduced expression of fatty acid synthase. In addition, quercetin suppressed the phosphorylation of c-Met downstream molecules including Gab1 (GRB2-associated-binding protein 1), FAK (Focal Adhesion Kinase) and PAK (p21-activated kinases). More importantly, overexpression of FAK or PAK significantly reduced the inhibitory effect of quercetin on the migration of the melanoma cells.

Conclusions: Our findings suggest that suppression of the HGF/C-Met signaling pathway contributes to the anti-metastatic action of quercetin in melanoma.

Keywords: Quercetin, Melanoma, Migration, Invasion, Metastasis, c-Met

\section{Background}

The incidence and mortality rates of melanoma have increased world-wide in the last 30 years [1]. Melanoma is notorious for its propensity to metastasize. Early stage melanoma is readily treatable, but advanced metastatic melanoma becomes resistant to treatment. It is reported that the long-term survival rate for patients with metastatic melanoma is only 5\% [2]. Currently available chemotherapeutic approaches for melanoma often carry

\footnotetext{
* Correspondence: zlyu@hkbu.edu.hk

Jockey Club School of Chinese Medicine Building, 7 Baptist University Road, Kowloon Tong, Kowloon, China
}

\section{Ciomed Central}

tolerance, low response rate [3] and high toxicity [4,5]. New targeted therapies with high response rate and low toxicity are urgently needed for managing malignant melanoma.

Recently, the role of receptor tyrosine kinase c-Met in melanoma pathogenesis has been gaining interest. c-Met is a cell surface receptor consists of a $50-\mathrm{kDa}$ extracellular $\alpha$ chain and a $140-\mathrm{kDa}$ membrane-spanning $\beta$ chain, and is synthesized from a single-chain $170-\mathrm{kDa}$ precursor [6]. Binding of HGF (hepatocyte growth factor), the only known endogenous ligand of c-Met [7], to c-Met leads to 
c-Met homo-dimerization and auto-phosphorylation. The phosphorylated regions of c-Met then act as the multifunction docking site for adaptor molecules which propagate a signaling cascade through a number of effector proteins [8]. Dysregulation of c-Met has been found in many types of cancer, which usually correlated with a poor prognosis [9]. Interestingly, abnormal activation of c-Met signaling is implicated in the acquisition of tumorigenic and metastatic phenotypes in tumors $[10,11]$. Examinations indicated that c-Met was expressed and activated in melanoma tissues and cell lines [12]. Studies showed that overexpression of c-Met was associated with melanoma growth and metastasis $[13,14]$. Constitutive activation of c-Met signaling has been reported to promote melanoma metastasis in mice $[15,16]$, while inhibition of c-Met signaling with a specific small molecule tyrosine kinase inhibitor reduced growth and metastasis of experimental human melanoma $[17,18]$. Blockade of c-Met signaling with the specific small interfering (si) RNA also induced melanoma cell differentiation and prevented melanoma metastasis in a mouse model $[17,18]$. These studies suggest that c-Met is a therapeutic target for melanoma metastasis.

The dietary flavonoid quercetin (3,3,4,5,7-pentahydroxyflavone) is a bioactive compound that wildly distributed in the plant kingdom. It possesses low intrinsic toxicity and does not have carcinogenic activity in vivo [19]. Besides, it has a relatively high oral bioavailability [20]. Quercetin has many biological functions including anti-melanoma activity [21]. Several studies showed that quercetin inhibited melanoma growth [22-24] and metastasis [25,26]. Moreover, quercetin also inhibited HGF-induced c-Met phosphorylation in human medulloblastoma cell line DAOY [27], and suppressed HGFstimulated migration and invasion in DAOY cells [27] and human hepatoma HepG2 cells [28].

Our published data [29] demonstrated that quercetin inhibited melanoma cell migration and invasion in vitro and prevented melanoma lung metastasis in vivo. Here, we show that quercetin inhibits HGF/c-Met signaling manifested by suppressing c-Met phosphorylation, interfering c-Met dimerization, reducing c-Met protein expression and attenuating the activities of downstream molecules including Gab1, FAK and PAK, which contributes to the anti-metastatic action of quercetin in melanoma.

\section{Results}

\section{Quercetin suppressed HGF-stimulated melanoma cell migration and invasion}

The effects of quercetin on HGF-stimulated melanoma cell migration and invasion were determined by the Transwell chamber assays. As shown in Figure 1A, HGF significantly enhanced the migratory abilities in melanoma
A2058 and A375 cells. After a 24-h stimulation with HGF, the numbers of A2058 and A375 cells that migrated through the membranes were 4.3 -fold and 1.8-fold more than that under unstimulated condition, respectively. A 48-h stimulation with HGF also caused a significant increase in cell migration, whereas treatment with quercetin reduced cell migratory abilities in a dose-dependent manner. In parallel, a Matrigel invasion assay showed that stimulation with HGF significantly increased the invasiveness of melanoma cells at both $24 \mathrm{~h}$ - and $48 \mathrm{~h}$-incubation periods, and this effect was dose-dependently reverted by quercetin treatments (Figure 1B). Under all these conditions, quercetin did not affect cell proliferation (Additional file 1: Figure S1). These results indicate that quercetin dose-dependently inhibits HGF-stimulated melanoma cell migration and invasion.

\section{Quercetin reduced c-Met phosphorylation and dimerization}

It has been reported that activation of the HGF/c-Met pathway promotes cell invasion, migration and allows cancer metastasis [9]. Therefore, we examined if quercetin inhibited the HGF/c-Met signaling pathway. Cells were treated with either the vehicle or quercetin $(60 \mu \mathrm{M})$ for $6 \mathrm{~h}$, and then stimulated with or without HGF (100 ng/ml) for $10 \mathrm{~min}$. Figure 2A showed that unstimulated cells had low c-Met phosphorylation level at the major auto-phosphorylation sites Tyr1234/5, while stimulation with HGF significantly increased c-Met phosphorylation. Interestingly, pre-treatment with quercetin reduced the phosphorylation of c-Met in the HGFstimulated cells. To eliminate the influence of serum growth factors, cells were grown in serum-free medium overnight and then treated with either the vehicle or quercetin $(60 \mu \mathrm{M})$ for $6 \mathrm{~h}$ before stimulating with $100 \mathrm{ng} / \mathrm{ml} \mathrm{HGF}$ for $10 \mathrm{~min}$. Data from the Western blot analysis showed that c-Met hardly phosphorylated in starved cells and stimulation with HGF remarkably increased c-Met phosphorylation levels at the Tyr1234/5 sites and the multi-substrate docking site Tyr1349, whereas pre-incubation with quercetin decreased the phosphorylation levels of c-Met in the HGF-stimulated cells (Figure 2B). In addition, we observed that total cMet expression levels were reduced by quercetin treatment (Figure 2A and $\mathrm{B}$ ).

Next, we determined if quercetin affected c-Met dimerization. As shown in Figure 2C, incubation with a cross linker $\mathrm{BS}^{3}$ increased c-Met dimerization (lane 3 versus 1 ), while pretreatment with quercetin reduced the expression level of c-Met dimer (lane 4 versus 3). Besides, stimulation with HGF caused an apparent c-Met dimerization (lane 5 versus 3), which was also inhibited by quercetin pre-incubation (lane 6 versus 5). 


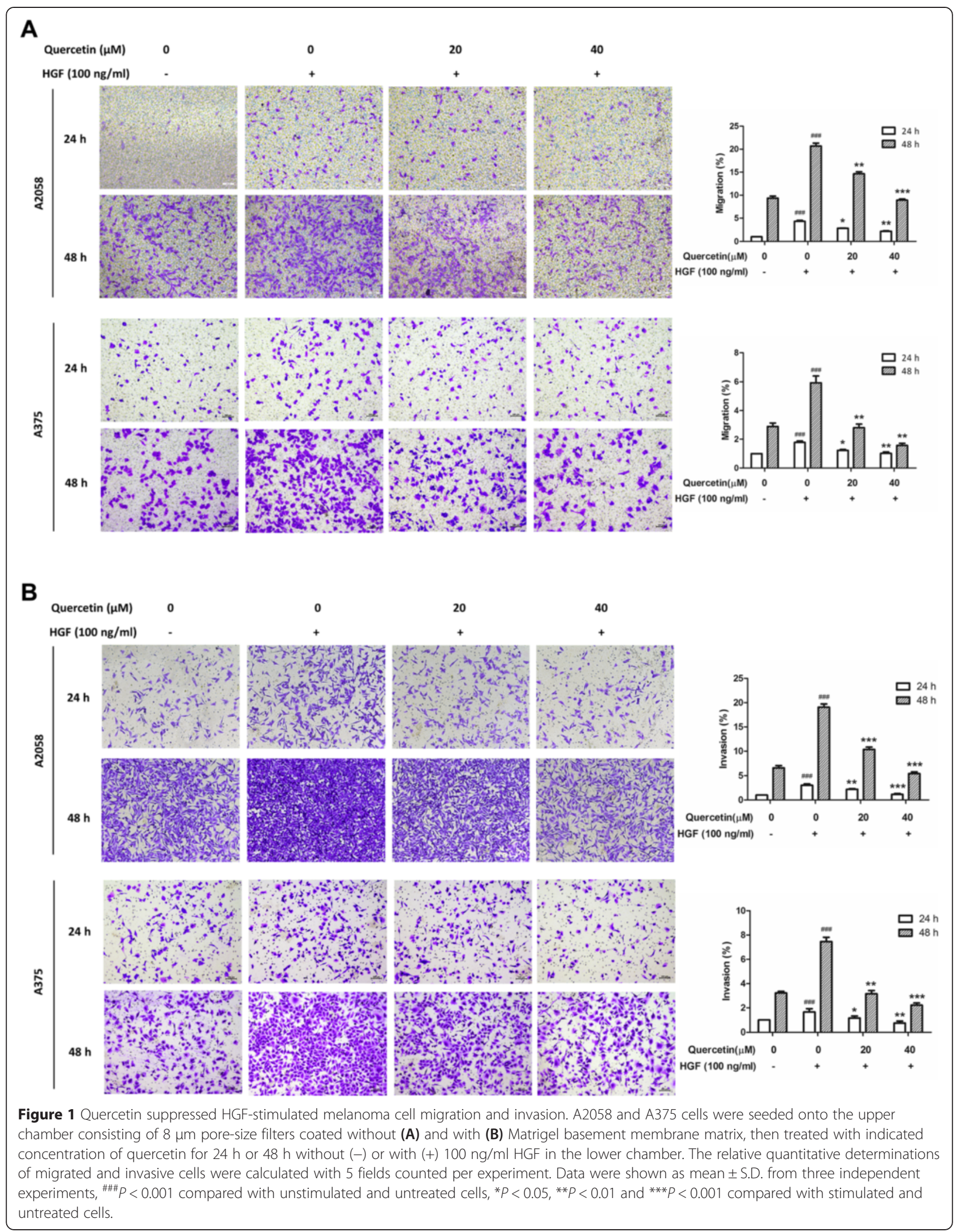




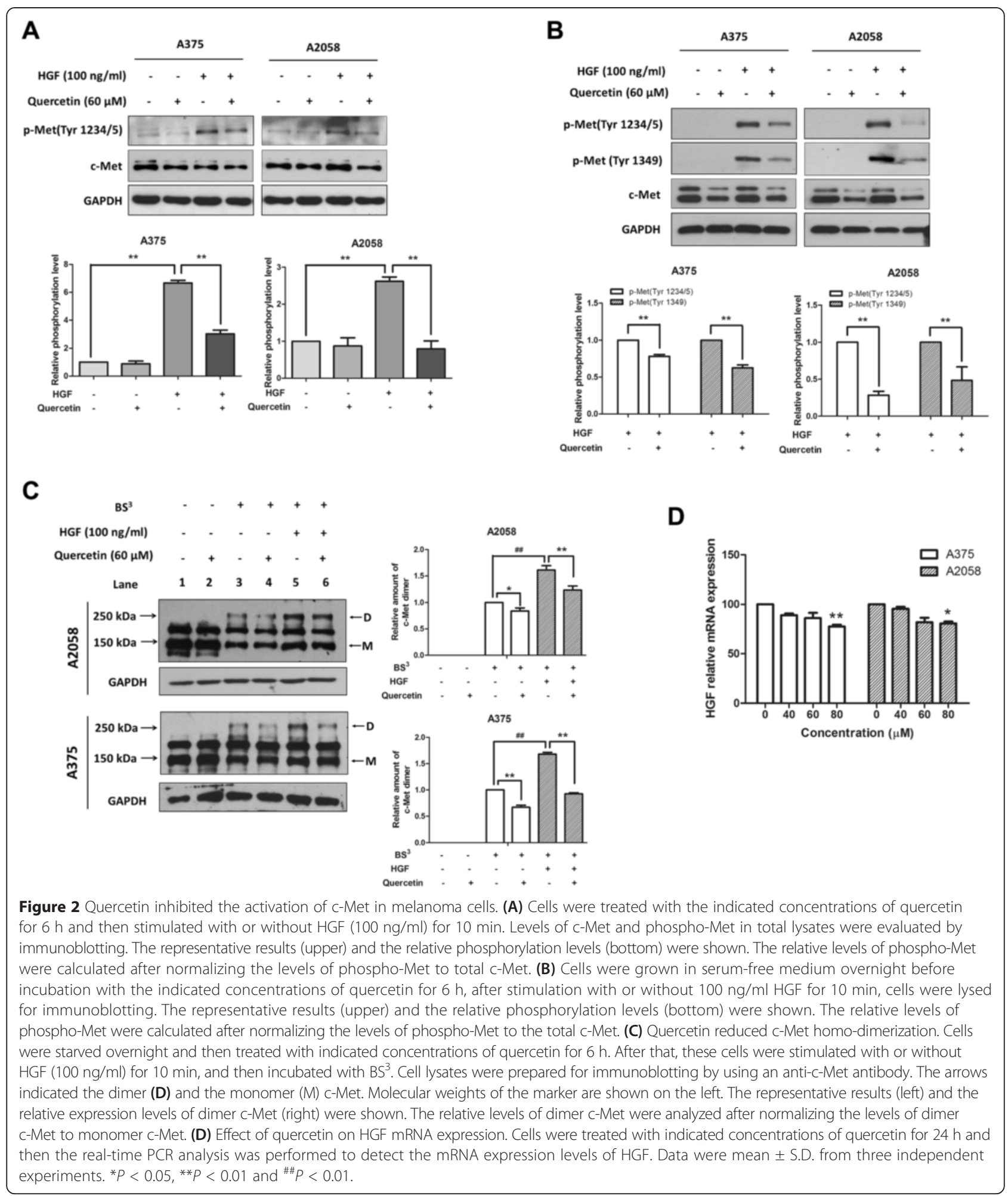

It is reported that most of melanoma cells produce HGF that induces sustained activation of its receptor cMet [30]. We wondered if quercetin affected the endogenous HGF expression level. Real-time PCR data showed that the mRNA expression levels of HGF in melanoma A375 and A2058 cells were slightly reduced after treating with quercetin for $24 \mathrm{~h}$ (Figure 2D).

Taken together, these findings suggest that quercetin inhibits c-Met activation probably mainly by inhibiting c-Met phosphorylation and dimerization. 
The inhibitory effect of quercetin on c-Met expression was associated with reduced expression of fatty acid synthase

To verify the effect of quercetin on c-Met expression, we performed the Western blot analysis in melanoma MeWo and sk-mel-2 cells in addition to A375 and A2058 cells. Whole-cell lysates from the four cells treated with various concentrations of quercetin $(0,40,60$ and $80 \mu \mathrm{M})$ for $24 \mathrm{~h}$, or a fixed concentration $(60 \mu \mathrm{M})$ for various durations $(0,3,6$ and $12 \mathrm{~h})$ were immuno-blotted with the c-Met antibody. We found that quercetin reduced c-Met expression in both dose- and timedependent manners in these four cell lines (Figure 3A and B). Since c-Met is a membrane receptor tyrosine kinase, we examined if quercetin inhibited cell surface c-Met expression. After treating A375 and A2058 cells with the indicated concentrations of quercetin for $24 \mathrm{~h}$, we isolated the membrane and cytosolic fractions for Western blot analyses. As shown in Figure 3C, the expression levels of c-Met were dose-dependently reduced by quercetin in both membrane and cytosolic fractions of the A375 and A2058 cells.

It has been reported that palmitate whose synthesis requires fatty acid synthase (FAS) involvement is essential for maintaining c-Met expression, and inhibition of FAS using inhibitors or the shRNA knockdown greatly reduces c-Met expression [31]. The activity of FAS is tightly correlated with melanoma progression and metastasis. Studies showed that malignant melanomas expressed higher levels of FAS than nevi, and metastatic melanomas expressed the highest levels of FAS [32]. Moreover, increased FAS expression was usually associated with melanoma invasion depth and poor patient survival [32-34]. Quercetin has been reported to inhibit FAS activity, which was associated with quercetinmediated prostate cancer cell apoptosis [35]. Quercetin also reduced FAS expression levels and inhibited cell proliferation in nasopharyngeal carcinoma cells [36]. Interestingly, in this study, quercetin not only downregulated c-Met expression levels, but also reduced FAS expression in human melanoma A375, A2058, MeWo and sk-mel-2 cells (Figure 3D). We suggested that quercetinafforded down-regulation of c-Met was probably caused by inhibiting FAS. As expected, C75, a specific inhibitor of FAS, inhibited c-Met with kinetics similar to that for inhibiting FAS (Figure 3E). More importantly, addition of palmitate reduced quercetin-mediated c-Met reduction in a dose-dependent manner (Figure 3F). These results suggest that inhibition of FAS expression contributes to the inhibitory effect of quercetin on c-Met expression.

\section{Quercetin suppressed the activation of c-Met downstream molecules}

After phosphorylation, c-Met recruits adaptor protein Gab1 (Grb2-associated binding protein 1), phosphorylates
Gab1 at tyrosine site 307 and hence activates downstream FAK (Focal Adhesion Kinase) and PAK (p21-activated kinase). Activation of FAK and PAK pathways results in increased cell motility, migration and invasion [9]. To determine if quercetin inhibited the c-Met downstream molecules, A375 and A2058 cells were treated with various concentrations of quercetin for $24 \mathrm{~h}$ and the wholecell lysates were prepared for Western blot analyses. We found that the levels of phosphorylated Gab1 at the tyrosine 307 (Tyr307) site in both A375 and A2058 cells were reduced in a dose-dependent manner (Figure 4A), and the activation of both FAK and PAK were inhibited by quercetin treatment in a dose-dependent manner (Figure $4 \mathrm{~B}$ and C). To eliminate the influence of serum growth factors, cells were starved overnight and treated with either the vehicle or quercetin $(60 \mu \mathrm{M})$ in serum-free medium for $6 \mathrm{~h}$, followed by stimulation with HGF $(100 \mathrm{ng} / \mathrm{ml})$ for $10 \mathrm{~min}$. Western blot analyses showed that under the starved conditions, the phosphorylation of Gab1 was significantly reduced in A2058 cells, while stimulation with HGF resulted in a remarkable increase in Gab1 phosphorylation which was completely abolished by quercetin pretreatment (Figure 4D, left). The activation of FAK and PAK in A2058 cells were significantly inhibited by quercetin under both HGF-stimulated and unstimulated conditions (Figure 4D, middle and right). These data demonstrate that quercetin suppresses the activation of c-Met downstream molecules Gab1, FAK and PAK.

\section{The inhibitory effect of quercetin on cell migration was partially reversed by PAK or FAK overexpression}

To better understand the involvement of c-Met signaling in quercetin-mediated anti-metastatic effects, we investigated whether overexpression of PAK or FAK reversed the quercetin-mediated inhibitory effect on migration. A2058 cells were transiently transfected with either a FAK-expressing construct (or a PAK-expressing construct) or an empty vector. After $24 \mathrm{~h}$ transfection, the expression of FAK and phospho-FAK were increased remarkably, and the quercetin-mediated FAK inhibition was also partially reversed (Figure 5A and B). Similar results were observed in the PAK-expressing construct transfected cells, overexpression of PAK reversed quercetin-induced FAK inhibition (Figure $5 \mathrm{~A}$ and $\mathrm{B}$ ). Furthermore, cells that transfected with PAK or FAK constructs showed a slight but significant increase in the migratory abilities as compared with cells that were transfected with empty vector $\left({ }^{\#} P<0.05\right)$. Quercetin treatment $(40 \mu \mathrm{M})$ inhibited the cell migratory abilities. This inhibitory effect was reduced from $48 \%$ to $33 \%$ in PAK overexpressing cells, and from $48 \%$ to $30 \%$ in FAK overexpressing cells. These data indicate that the inhibitory effect of quercetin on migration is partially reduced by the overexpression of PAK or FAK in melanoma cells. 


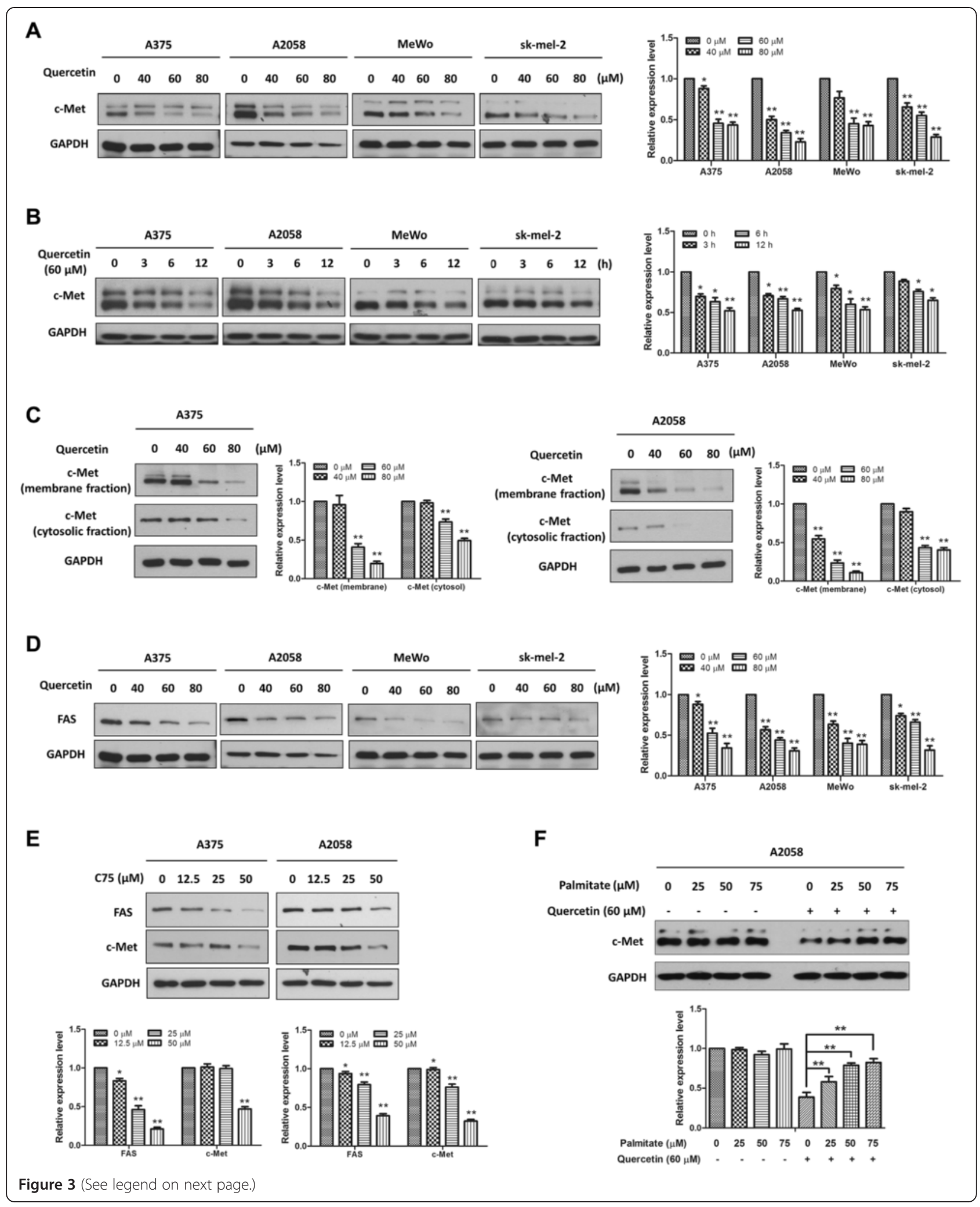


(See figure on previous page.)

Figure 3 Quercetin reduced c-Met levels through the inhibition of FAS. A375, A2058, MeWo and sk-mel-2 cells were treated with (A) various concentrations of quercetin for $24 \mathrm{~h}$ or (B) a fixed concentration $(60 \mu \mathrm{M})$ for various durations, and then the whole-cell lysates were prepared and the Western blot analysis was performed to determine the expression level of c-Met. (C) A375 and A2058 cells were treated with indicated concentrations of quercetin for $24 \mathrm{~h}$, and then the membrane and cytosolic lysates were prepared. The expression levels of c-Met in the two fractions were examined by immunoblotting. (D) A375, A2058, MeWo and sk-mel-2 cells were treated with indicated concentrations of quercetin for $24 \mathrm{~h}$, and then the expression of FAS were determined by immunoblotting. (E) A375 and A2058 cells were treated with indicated concentrations of $\mathrm{C} 75$ for $24 \mathrm{~h}$ and then the immunoblotting assay was conducted to determine the expression levels of FAS and c-Met. (F) A2058 cells were exposed to either the vehicle or $60 \mu \mathrm{M}$ quercetin for $24 \mathrm{~h}$ in the absence or presence of palmitate, and then the whole-cell lysates were prepared for immunoblotting by using a c-Met antibody. Independent experiments were performed at least three times, and the results from a representative experiment are shown. The relative expression levels were analyzed by Image J software and shown as mean \pm S.D., ${ }^{*} P<0.05,{ }^{* *} P<0.01$.

\section{Discussion}

The HGF/c-Met pathway is activated in various types of cancer, which stimulates cancer cell growth and metastasis [9]. HGF is a multifunctional cytokine acting as a mitogen, motogen and morphogen [37]. Most cancers express both HGF and c-Met, leading to autocrine activation of c-Met. Besides, aberrant c-Met activation can also be achieved through c-Met overexpression, activating c-Met mutations, or c-Met gene amplification [38]. In melanoma, HGF and c-Met are expressed [9] and involved in tumorigenesis [30]. In this study, we found that quercetin, a widely existed dietary flavonoid, suppressed c-Met signaling by inhibiting c-Met phosphorylation and dimerization (Figure 2A, B and C). Quercetin also inhibited HGF-stimulated melanoma cell migration and invasion (Figure 1), which was in agreement with the previous studies that quercetin inhibited HGFstimulated migration and invasion in human medulloblastoma cell DAOY [27] and human hepatoma HepG2 cells [28]. In addition, many other known flavonoids, such as EGCC [39], luteolin [28,31], kaempferol [27] and myricetin [27] also showed inhibitory effects on HGFstimulated cancer cells migration. These observations indicated that these plant-derived flavonoids shared similar activities and may be useful in melanoma treatment and prevention.

Since some melanoma cells were reported to express HGF and secret a detectable level of HGF to induce constitutive activation of c-Met [30], we wondered if quercetin exerted its effects by affecting HGF autocrine. We collected the culture medium of quercetin-treated A375 and A2058 cells, and examined the HGF levels by ELISA, but the level of secreted HGF was too low to be detected. Besides, we also found that the inhibitory effect of quercetin on HGF mRNA expression was not obvious (Figure 2D). Based on these results we could not draw a conclusion regarding the impact of HGF autocrine on quercetin-mediated c-Met signaling inhibition.

We found that c-Met protein levels were decreased after quercetin treatment in both dose- and timedependent manners (Figure 3A and B). Since melanoma can be divided into three mutually exclusive genetic subsets: BRAF mutant melanoma, NRAS mutant melanoma and melanoma of wild type at both loci [40], to confirm the generality of this finding, beside two BRAF mutant melanoma cell lines A375 and A2058, NRAS mutant melanoma cell line sk-mel-2 and wild type NRAS and BRAF melanoma cell line MeWo with constant c-Met activation [12] were also used. Results showed that treatment with quercetin down-regulated the expression levels of c-Met in all these four cell lines (Figure 3A and $B$ ), suggesting that the inhibitory effect of quercetin on c-Met receptor is a general phenomenon in melanoma. It was further found that c-Met expression was higher in membrane fractions than in cytosol fractions, and c-Met in both fractions were inhibited by quercetin treatment (Figure 3C). We also found that quercetin did not affect the mRNA expression levels of c-Met in all these cell lines (data not shown), which indicated that quercetin post-transcriptionally down-regulated cMet expression. Coleman et al. identified a regulatory link between FAS and c-Met. They found that inhibition of FAS by using inhibitors (luteolin or C75) or the shRNA knockdown approach can down-regulate c-Met expression in human prostate cancer cells, and the production of the 16-carbon fatty acid palmitate by FAS is required for maintaining c-Met expression [31]. Similar results have also been observed in diffuse large $B$ cell lymphoma by Uddin et al. [41] and in breast cancer by Hung et al. [42]. Furthermore, Coleman et al. found that all the flavonoids luteolin, apigenin, and quercetin, which possess a same moiety with a C2-C3 double bond in the C-ring, reduced c-Met expression in human prostate cancer cells [31]. In this study, we found that quercetin reduced c-Met expression, C75, a specific inhibitor of FAS, showed similar inhibitory effect on the expression of FAS and c-Met (Figure 3E), and exogenous palmitate prevented quercetin-induced reduction of c-Met (Figure 3F), further supporting a role of FAS in maintaining c-Met expression levels. However, the mechanism by which FAS inhibition decreases c-Met expression is not yet clear. A possible explanation is that FAS inhibition may cause an imbalance in the membrane phospholipids levels, which may result in decreased c-Met membrane localization $[41,43]$. Lipid rafts are membrane microdomains that serve as platforms for cell signaling, 


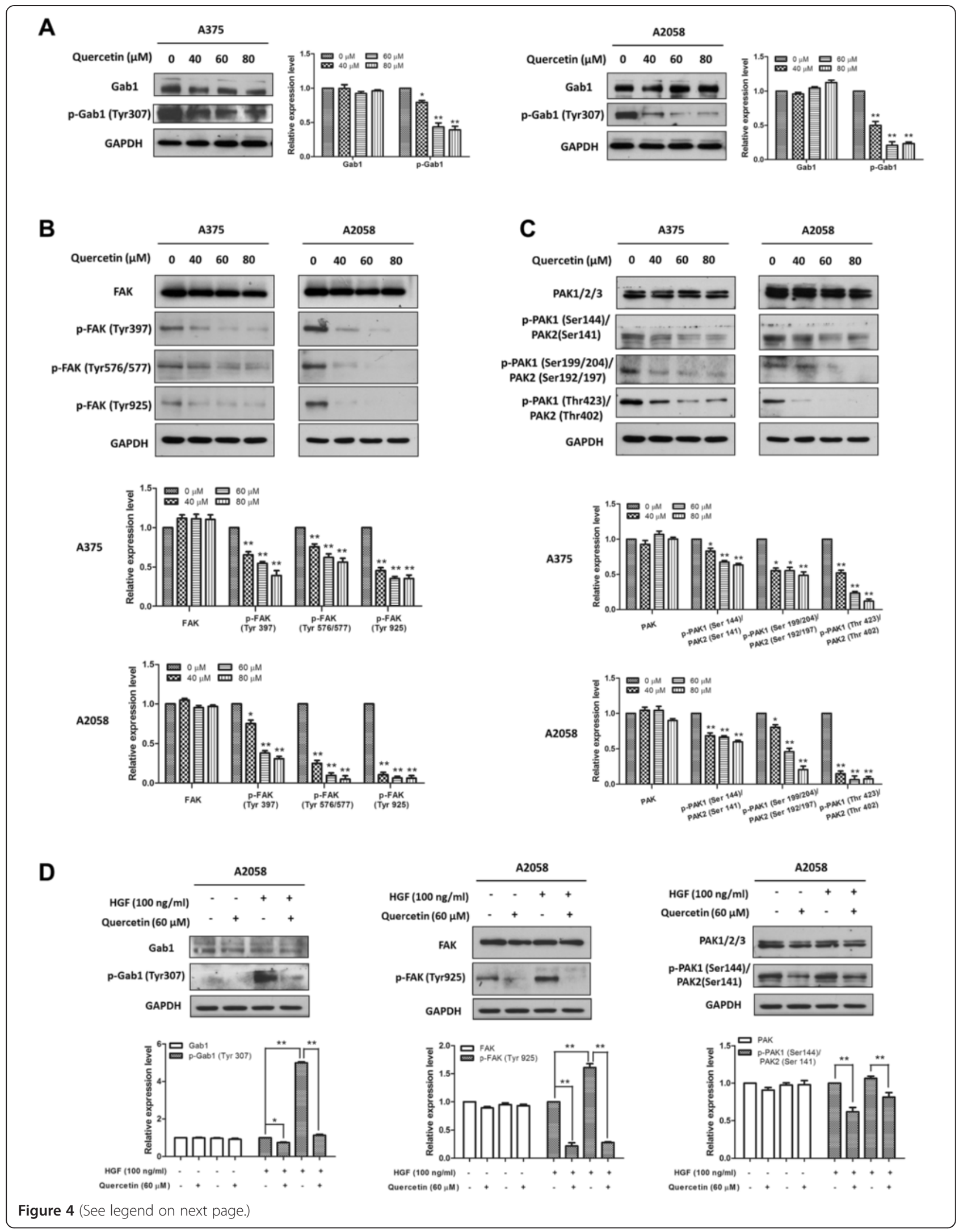


(See figure on previous page.)

Figure 4 Quercetin suppressed the activation of c-Met downstream molecules. (A, B and C) A375 and A2058 cells were treated with indicated concentrations of quercetin for 24 h. (D) A2058 cells were starved overnight and then exposed to the vehicle or quercetin $(60 \mu \mathrm{M})$ for 6 h. After that, these cells were stimulated with or without HGF $(100 \mathrm{ng} / \mathrm{ml})$ for $10 \mathrm{~min}$. For each experiment, the whole-cell lysates were prepared and probed by Western blot using specific antibodies. Independent experiments were performed at least three times, and the results from a representative experiment are shown. The relative expression levels were analyzed by Image J software and shown as mean \pm S.D., ${ }^{*} P<0.05$, ${ }^{* *} P<0.01$.

and FAS was shown to regulate the activity of lipid rafts [44]. Recent studies found that altering the structure or function of lipid rafts prevented the activation of c-Met [45]. Quercetin is also reported to suppress lipid biosynthesis in breast cancer MDA-MB-231 cells [35]. Therefore, the quercetin-mediated reduction of c-Met in melanoma cells may be due to FAS inhibition.

After phosphorylation on tyrosine site 1349, c-Met becomes a docking site for recruiting Gab1, which further activates downstream FAK and PAK [9]. Activation of both c-Met/Gab1/FAK and c-Met/Gab1/PAK signalings promotes tumor metastasis [9]. Our data showed that quercetin dose-dependently decreased the levels of phospho-Gab1, phospho-FAK and phospho-PAK (Figure 4A, B and C), suggesting that inhibition of the c-Met/Gab1/FAK and c-Met/Gab1/PAK pathways may contribute to the anti-metastatic effects of quercetin. It is well-known that quercetin has multiple targets including receptor tyrosine kinases, matrix metalloproteinase, mitochondria and other signaling enzymes [46]. Besides Gab1, c-Met can also activate other molecules such as STAT3 [8] which is involved in melanoma metastasis. STAT3 can be suppressed by quercetin treatment as shown in our previous study [29]. Therefore, we could not exclude the possibilities that quercetin inhibits melanoma metastasis by modulating other pathways downstream of c-Met. Indeed, overexpression of FAK or PAK only partially reversed quercetin-mediated inhibitory effects on melanoma cell migration (Figure 5C). Whether overexpression of both PAK and FAK can completely reverse the migration inhibitory effect of quercetin in melanoma cells needs to be further studied.

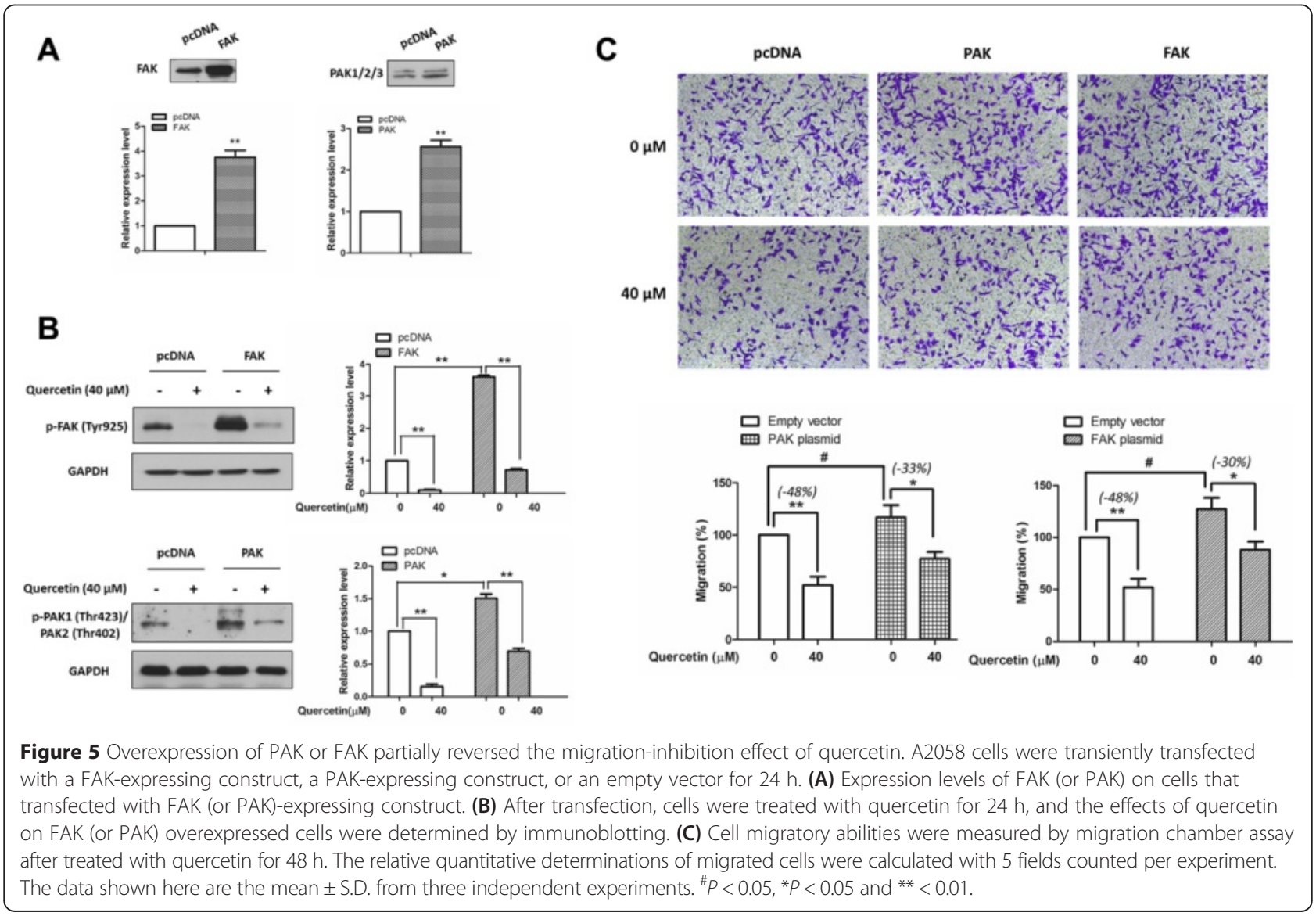




\section{Conclusions}

In summary, our previous [29] and current studies show that quercetin suppresses melanoma cell migration and invasion. This effect is, at least in part, due to the inhibition of $\mathrm{HGF} / \mathrm{c}-\mathrm{Met}$ signaling. Our findings provide novel insights into the anti-melanoma molecular mechanisms of quercetin, and further suggest a potential role of quercetin in melanoma management.

\section{Methods}

\section{Reagents and antibodies}

Antibodies against phospho-Met (Tyr1234/Y1235), phosphoMet (Tyr1349), phospho-Met (Tyr1003), c-Met, phosphoGab1 (Tyr307), FAK, phospho-FAK (Tyr576/577), phospho-FAK (Tyr925), phospho-FAK (Tyr397), PAK1/ 2/3, phospho-PAK1 (Ser144)/PAK2 (Ser141), phosphoPAK1 (Ser199/204)/PAK2 (Ser192/197), phospho-PAK1 (Thr423)/PAK2 (Thr402) and FAS were obtained from Cell Signaling Technology (Beverly, MA, USA). AntiGAPDH was purchased from Santa Cruz Biotechnology (Santa Cruz, CA, USA). Goat anti-rabbit IgG, goat antimouse IgG and protein markers were supplied by BioRad (Hercules, CA, USA). Recombinant human HGF was obtained from PeproTech (PeproTech, NJ, USA). Other chemicals were obtained from Sigma-Aldrich (St. Louis, MO, USA). Quercetin was obtained from Chromadex (USA). The stock solution of $100 \mathrm{mM}$ quercetin was prepared in dimethyl sulfoxide (DMSO) and stored at $-20^{\circ} \mathrm{C}$. Palmitate was complexed to bovine serum albumin as previously described [47]. In short, sodium palmitate was dissolved in ethanol: $\mathrm{H}_{2} \mathrm{O}$ $(1: 1, \mathrm{v} / \mathrm{v})$ at $70^{\circ} \mathrm{C}$ at a final concentration of $150 \mathrm{mM}$, then the solutions were complexed with fatty-acid-free BSA ( $10 \%$ solution in $\mathrm{H}_{2} \mathrm{O}$ ) by stirring for $1 \mathrm{~h}$ at $37^{\circ} \mathrm{C}$ and then diluted in culture medium. The final molar ratio of fatty acid:BSA was 5:1.

\section{Cell culture}

A375, A2058, sk-mel-2 and MeWo cell lines were obtained from the American Type Culture Collection (ATCC, USA), and were incubated in high glucose Dulbecco's modified Eagle's medium (DMEM, GIBCO, USA), supplemented with $10 \%(\mathrm{v} / \mathrm{v})$ fetal bovine serum (FBS, GIBCO, USA) and $1 \%$ penicillin/streptomycin $(\mathrm{P} / \mathrm{S}, \mathrm{GIBCO}, \mathrm{USA})$ at $37^{\circ} \mathrm{C}$ in a humidified atmosphere of $5 \% \mathrm{CO}_{2}$.

\section{Cell migration and invasion assay}

The cell migratory ability was tested using a commercial Transwell insert ( $8 \mu \mathrm{m}$ pore size, Corning, NY, USA). A2058 and A375 cells were suspended in serum-free DMEM medium containing $0.1 \%$ BSA. Then $0.1 \mathrm{ml}$ of the cells suspension was added to the top of the Transwell inserts, and $0.5 \mathrm{ml}$ of serum-containing medium with $(+)$ or without $(-)$ HGF $(100 \mathrm{ng} / \mathrm{ml})$ was plated in the bottom wells. Quercetin was added to both inserts and wells. The chambers were then assembled and incubated for $24 \mathrm{~h}$ or $48 \mathrm{~h}$ at $37^{\circ} \mathrm{C}$ in a $5 \% \mathrm{CO}_{2}$ incubator. After that, non-invading cells were removed from the upper surface of the membrane by scrubbing. The migrated cells on the underside of the filter were first fixed with $100 \%$ methanol and then stained by $0.1 \%$ crystal violet solution and counted in five random fields. The relative migration was calculated from the ratio of the migrated cells that quercetin treated versus the vehicle control cells.

For the invasion assay, BD BioCoat ${ }^{\mathrm{m}} \mathrm{Matrige} \mathrm{I}^{\mathrm{m}}$ invasion chamber (24 well plate, $8-\mu \mathrm{m}$ pore size, BD Biosciences, San Jose, CA, USA) were used. $0.5 \mathrm{ml}$ warm $\left(37^{\circ} \mathrm{C}\right)$ serum-free medium was added to both the inserts and the wells to allow the chamber rehydrated at $37^{\circ} \mathrm{C}$ in a $5 \% \mathrm{CO}_{2}$ incubator for $2 \mathrm{~h}$. Then A2058 and A375 cells in $0.5 \mathrm{ml}$ serum-free medium containing $0.1 \%$ BSA were added to the inserts, while $0.75 \mathrm{ml}$ of serum-containing medium with or without HGF $(100 \mathrm{ng} / \mathrm{ml})$ was placed in the lower chambers. Quercetin was added to both the inserts and the lower chambers. Chambers were then assembled and incubated for $24 \mathrm{~h}$ or $48 \mathrm{~h}$ at $37^{\circ} \mathrm{C}$. Subsequent steps were performed in the same manner as described for cell migration assay.

\section{Western blot analysis}

Membrane protein was extracted using Mem-PER ${ }^{\mathrm{Tm}}$ Plus kit (Thermo Scientific, Rockford, IL, USA) according to the manufacturer's protocol. Preparation of total protein lysates and Western blot analysis were performed as described previously [29]. Protein concentrations were determined according to the Bio-Rad protein assay reagent. The cell lysates were separated on $6 \%$ or $8 \%$ gels and transferred to nitrocellulose membranes. The membranes were incubated in 5\% skim milk in TBS-T buffer at room temperature. Blocked membranes were incubated with primary antibodies at $4^{\circ} \mathrm{C}$ overnight, followed by incubation with secondary antibodies at room temperature for 1 hour. After washing in TBS-T, immunereactive bands were visualized by chemiluminescence substrate (Thermo Scientific, Rockford, IL, USA).

\section{Real-time PCR}

Total RNA was extracted with Trizol reagent (Invitrogen, USA), and reverse-transcripted with oligo-dT using MMLV reverse transcriptase (Promega, USA) according to the manufacturer's protocol. Quantitative real time PCR was carried out by monitoring the increase in fluorescence of SYBR green with the ViiA 7 Real Time PCR System (Applied Biosystems, USA). The primer sets were synthesized by Invitrogen, HGF primers: forward TCCCCATCG CCATCCCC and reverse CACCATGGCCTCGGCTGG, 
GAPDH primers: forward CTGCACCACCAACTGCTT AGC and reverse CTTCACCACCTTCTTGATGTC. Each sample was amplified in triplicate for quantification. Data were analyzed by relative quantitation using the $\Delta \Delta \mathrm{C}_{\mathrm{t}}$ method and normalized to GAPDH.

\section{Dimerization of c-Met}

The dimerization of c-Met was analyzed as described previously [48]. Melanoma cells were starved overnight and then treated with vehicle control or quercetin for $6 \mathrm{~h}$, followed by stimulation with HGF $(100 \mathrm{ng} / \mathrm{ml})$ on ice for $10 \mathrm{~min}$. Subsequently, the crosslinker Bis[sulfosuccinimidyl] substrate $\left(\mathrm{BS}^{3}, 0.25 \mathrm{mM}\right.$, Thermo Scientific, Rockford, IL, USA) was added to cells and reacted at $37^{\circ} \mathrm{C}$ for $5 \mathrm{~min}$. Cells were then transferred on ice for $10 \mathrm{~min}$. After that, non-reactive $\mathrm{BS}^{3}$ were quenched with $50 \mathrm{mM}$ Tris- $\mathrm{HCl}(\mathrm{pH}$ 7.4). Cell lysates were separated by $6 \%$ SDS-PAGE and immunoblotted with an anti-c-Met antibody.

\section{Plasmid transient transfection}

Plasmids pCMV6M-Pak1 (Addgene plasmid 12209) was provided by Sells et al. [49] and myc-Rapr-FAK (Addgene plasmid 25926) was supplied by Karginov et al. [50]. To overexpress FAK and PAK, cells were transfected with plasmids using Lipofectamine 2000 (Invitrogen, USA) according to the manufacturer's protocol. Empty pcDNA3.0 plasmid was used as mock transfectant. Cells were transfected with plasmids for $24 \mathrm{~h}$ or $48 \mathrm{~h}$ before functional assays were carried out.

\section{Statistical analysis}

The Student's $t$-test was used to analyze differences between two groups. All data were presented as means \pm S.D. from at least three independent experiments. $P<0.05$ was considered as statistically significant.

\section{Additional file}

Additional file 1: Figure S1. Effect of quercetin on melanoma cell proliferation. A375 and A2058 cells were treated with indicated concentrations of quercetin for $24 \mathrm{~h}$ or $48 \mathrm{~h}$. Cell viability was measured by the MTT assay. Data were mean \pm S.D. from three independent experiments.

\section{Abbreviations \\ $\mathrm{BS}^{3}$ : Bis[sulfosuccinimidyl] suberate; EGCG: (-)-epigallocatechin-3-gallate; ELISA: Enzyme-linked immunosorbent assay; FAK: Focal adhesion kinase; FAS: Fatty acid synthase; Gab1: Grb2-associated binding protein 1; HGF: Hepatocyte growth factor; PAK: p21-activated kinase.}

\section{Competing interests}

The authors declare that they have no competing interests.

\section{Authors' contributions}

HC designed, carried out the experiments, analyzed data and drafted the manuscript. XF, HG, TL participated in the data analysis. HY, CC and TS contributed to the reagents and analysis tools. AT and ZY conceived of the study and participated in its design. HK and ZY helped to the final drafting of the manuscript. All authors read and approved the final manuscript.

\section{Acknowledgements}

This work was supported by the Research Grants Council of Hong Kong (HKBU 262512); Food and Health Bureau of Hong Kong (HMRF 11122521); Science, Technology and Innovation Commission of Shenzhen (JCYJ20120829154222473 and JCYJ20140807091945050); and the Hong Kong Baptist University (FRG1/1415/061 and FRG2/14-15/056).

Received: 2 January 2015 Accepted: 13 April 2015

Published online: 14 May 2015

\section{References}

1. Siegel R, DeSantis C, Virgo K, Stein K, Mariotto A, Smith T, et al. Cancer treatment and survivorship statistics, 2012. CA Cancer J Clin. 2012;62:220-41.

2. Cummins DL, Cummins JM, Pantle H, Silverman MA, Leonard AL, Chanmugam A. Cutaneous malignant melanoma. Mayo Clin Proc. 2006;81:500-7.

3. Serrone L, Zeuli M, Sega FM, Cognetti F. Dacarbazine-based chemotherapy for metastatic melanoma: thirty-year experience overview. J Exp Clin Cancer Res. 2000;19:21-34.

4. Alwan LM, Grossmann K, Sageser D, Van Atta J, Agarwal N, Gilreath JA. Comparison of acute toxicity and mortality after two different dosing regimens of high-dose interleukin-2 for patients with metastatic melanoma. Target Oncol. 2014;9:63-71.

5. Atkins MB, Lotze MT, Dutcher JP, Fisher Rl, Weiss G, Margolin $\mathrm{K}$, et al. Highdose recombinant interleukin 2 therapy for patients with metastatic melanoma: analysis of 270 patients treated between 1985 and 1993. J Clin Oncol. 1999;17:2105-16.

6. Tam NN, Chung SS, Lee DT, Wong YC. Aberrant expression of hepatocyte growth factor and its receptor, c-Met, during sex hormone-induced prostatic carcinogenesis in the Noble rat. Carcinogenesis. 2000;21:2183-91.

7. Tolbert WD, Daugherty-Holtrop J, Gherardi E, Vande Woude G, Xu HE. Structural basis for agonism and antagonism of hepatocyte growth factor. Proc Natl Acad Sci U S A. 2010;107:13264-9.

8. Organ SL, Tsao MS. An overview of the c-MET signaling pathway. Ther Adv Med Oncol. 2011:3:S7-S19.

9. Birchmeier C, Birchmeier W, Gherardi E, Vande Woude GF. Met, metastasis, motility and more. Nat Rev Mol Cell Biol. 2003;4:915-25.

10. Webb CP, Taylor GA, Jeffers M, Fiscella M, Oskarsson M, Resau JH, et al. Evidence for a role of Met-HGF/SF during Ras-mediated tumorigenesis/ metastasis. Oncogene. 1998;17:2019-25.

11. Peschard P, Park M. From Tpr-Met to Met, tumorigenesis and tubes. Oncogene. 2007;26:1276-85.

12. Chattopadhyay C, Ellerhorst JA, Ekmekcioglu S, Greene VR, Davies MA, Grimm EA. Association of activated c-Met with NRAS-mutated human melanomas. Int J Cancer. 2012;131:E56-65.

13. Natali PG, Nicotra MR, Di Renzo MF, Prat M, Bigotti A, Cavaliere R, et al. Expression of the c-Met/HGF receptor in human melanocytic neoplasms: demonstration of the relationship to malignant melanoma tumour progression. Br J Cancer. 1993;68:746-50.

14. Puri N, Ahmed S, Janamanchi V, Tretiakova M, Zumba O, Krausz T, et al. c-Met is a potentially new therapeutic target for treatment of human melanoma. Clin Cancer Res. 2007;13:2246-53.

15. Yu Y, Merlino G. Constitutive c-Met signaling through a nonautocrine mechanism promotes metastasis in a transgenic transplantation model. Cancer Res. 2002;62:2951-6.

16. Otsuka T, Takayama H, Sharp R, Celli G, LaRochelle WJ, Bottaro DP, et al. c-Met autocrine activation induces development of malignant melanoma and acquisition of the metastatic phenotype. Cancer Res. 1998;58:5157-67.

17. Kenessey I, Keszthelyi M, Kramer Z, Berta J, Adam A, Dobos J, et al. Inhibition of c-Met with the specific small molecule tyrosine kinase inhibitor SU11274 decreases growth and metastasis formation of experimental human melanoma. Curr Cancer Drug Targets. 2010;10:332-42.

18. Surriga O, Rajasekhar VK, Ambrosini G, Dogan Y, Huang R, Schwartz GK. Crizotinib, a c-Met inhibitor, prevents metastasis in a metastatic uveal melanoma model. Mol Cancer Ther. 2013;12:2817-26.

19. Okamoto T. Safety of quercetin for clinical application (Review). Int J Mol Med. 2005;16:275-8.

20. Gugler R, Leschik M, Dengler HJ. Disposition of quercetin in man after single oral and intravenous doses. Eur J Clin Pharmacol. 1975;9:229-34. 
21. Russo M, Spagnuolo C, Tedesco I, Bilotto S, Russo GL. The flavonoid quercetin in disease prevention and therapy: facts and fancies. Biochem Pharmacol. 2012;83:6-15.

22. Piantelli M, Maggiano N, Ricci R, Larocca LM, Capelli A, Scambia G, et al. Tamoxifen and quercetin interact with type II estrogen binding sites and inhibit the growth of human melanoma cells. J Invest Dermatol. 1995; 105:248-53.

23. Loizzo MR, Said A, Tundis R, Hawas UW, Rashed K, Menichini F, et al. Antioxidant and antiproliferative activity of Diospyros lotus L. extract and isolated compounds. Plant Foods Hum Nutr. 2009;64:264-70.

24. Rosner K, Ropke C, Pless V, Skovgaard GL. Late type apoptosis and apoptosis free lethal effect of quercetin in human melanoma. Biosci Biotechnol Biochem. 2006;70:2169-77.

25. Caltagirone S, Rossi C, Poggi A, Ranelletti FO, Natali PG, Brunetti M, et al. Flavonoids apigenin and quercetin inhibit melanoma growth and metastatic potential. Int J Cancer. 2000;87:595-600.

26. Piantelli M, Rossi C, lezzi M, La Sorda R, lacobelli S, Alberti S, et al. Flavonoids inhibit melanoma lung metastasis by impairing tumor cells endothelium interactions. J Cell Physiol. 2006;207:23-9.

27. Labbe D, Provencal M, Lamy S, Boivin D, Gingras D, Beliveau R. The flavonols quercetin, kaempferol, and myricetin inhibit hepatocyte growth factor-induced medulloblastoma cell migration. J Nutr. 2009;139:646-52.

28. Lee WJ, Wu LF, Chen WK, Wang CJ, Tseng TH. Inhibitory effect of luteolin on hepatocyte growth factor/scatter factor-induced HepG2 cell invasion involving both MAPK/ERKs and PI3K-Akt pathways. Chem Biol Interact. 2006;160:123-33.

29. Cao HH, Tse AK, Kwan HY, Yu H, Cheng CY, Su T, et al. Quercetin exerts anti-melanoma activities and inhibits STAT3 signaling. Biochem Pharmacol. 2014:87:424-34.

30. Li G, Schaider H, Satyamoorthy K, Hanakawa Y, Hashimoto K, Herlyn M. Downregulation of E-cadherin and Desmoglein 1 by autocrine hepatocyte growth factor during melanoma development. Oncogene. 2001;20:8125-35.

31. Coleman DT, Bigelow R, Cardelli JA. Inhibition of fatty acid synthase by luteolin post-transcriptionally down-regulates c-Met expression independent of proteosomal/lysosomal degradation. Mol Cancer Ther. 2009;8:214-24.

32. Kapur P, Rakheja D, Roy LC, Hoang MP. Fatty acid synthase expression in cutaneous melanocytic neoplasms. Mod Pathol. 2005;18:1107-12.

33. de Andrade BA, Leon JE, Carlos R, Delgado-Azanero W, Mosqueda-Taylor A, Graner E, et al. Expression of fatty acid synthase (FASN) in oral nevi and melanoma. Oral Dis. 2011;17:808-12.

34. Innocenzi D, Alo PL, Balzani A, Sebastiani V, Silipo V, La Torre G, et al. Fatty acid synthase expression in melanoma. J Cutan Pathol. 2003;30:23-8.

35. Brusselmans K, Vrolix R, Verhoeven G, Swinnen JV. Induction of cancer cell apoptosis by flavonoids is associated with their ability to inhibit fatty acid synthase activity. J Biol Chem. 2005;280:5636-45.

36. Daker M, Ahmad M, Khoo AS. Quercetin-induced inhibition and synergistic activity with cisplatin - a chemotherapeutic strategy for nasopharyngeal carcinoma cells. Cancer Cell Int. 2012;12:34.

37. Gherardi E, Sharpe M, Lane K, Sirulnik A, Stoker M. Hepatocyte growth factor/scatter factor (HGF/SF), the c-met receptor and the behaviour of epithelial cells. Symp Soc Exp Biol. 1993;47:163-81.

38. Ma PC, Maulik G, Christensen J, Salgia R. c-Met: structure, functions and potential for therapeutic inhibition. Cancer Metastasis Rev. 2003;22:309-25.

39. Bigelow RL, Cardelli JA. The green tea catechins, (-)-Epigallocatechin-3gallate (EGCG) and (-)-Epicatechin-3-gallate (ECG), inhibit HGF/Met signaling in immortalized and tumorigenic breast epithelial cells. Oncogene. 2006;25:1922-30.

40. Goydos JS, Mann B, Kim HJ, Gabriel EM, Alsina J, Germino FJ, et al. Detection of B-RAF and N-RAS mutations in human melanoma. J Am Coll Surg. 2005;200:362-70.

41. Uddin S, Hussain AR, Ahmed M, Bu R, Ahmed SO, Ajarim D, et al. Inhibition of fatty acid synthase suppresses c-Met receptor kinase and induces apoptosis in diffuse large B-cell lymphoma. Mol Cancer Ther. 2010;9:1244-55.

42. Hung CM, Kuo DH, Chou CH, Su YC, Ho CT, Way TD. Osthole suppresses hepatocyte growth factor (HGF)-induced epithelial-mesenchymal transition via repression of the c-Met/Akt/mTOR pathway in human breast cancer cells. J Agric Food Chem. 2011;59:9683-90

43. Menendez JA, Vellon L, Mehmi I, Oza BP, Ropero S, Colomer R, et al. Inhibition of fatty acid synthase (FAS) suppresses HER2/neu (erbB-2) oncogene overexpression in cancer cells. Proc Natl Acad Sci U S A. 2004;101:10715-20.
44. Swinnen JV, Van Veldhoven PP, Timmermans L, De Schrijver E, Brusselmans K, Vanderhoydonc F, et al. Fatty acid synthase drives the synthesis of phospholipids partitioning into detergent-resistant membrane microdomains. Biochem Biophys Res Commun. 2003;302:898-903.

45. Duhon D, Bigelow RL, Coleman DT, Steffan JJ, Yu C, Langston W, et al. The polyphenol epigallocatechin-3-gallate affects lipid rafts to block activation of the c-Met receptor in prostate cancer cells. Mol Carcinog. 2010;49:739-49.

46. Lamson DW, Brignall MS. Antioxidants and cancer, part 3: quercetin. Altern Med Rev. 2000;5:196-208.

47. Briaud I, Harmon JS, Kelpe CL, Segu VB, Poitout V. Lipotoxicity of the pancreatic beta-cell is associated with glucose-dependent esterification of fatty acids into neutral lipids. Diabetes. 2001;50:315-21.

48. Wu YM, Liu CH, Huang MJ, Lai HS, Lee PH, Hu RH, et al. C1GALT1 enhances proliferation of hepatocellular carcinoma cells via modulating MET glycosylation and dimerization. Cancer Res. 2013;73:5580-90.

49. Sells MA, Knaus UG, Bagrodia S, Ambrose DM, Bokoch GM, Chernoff J. Human p21-activated kinase (Pak1) regulates actin organization in mammalian cells. Curr Biol. 1997;7:202-10.

50. Karginov AV, Ding F, Kota P, Dokholyan NV, Hahn KM. Engineered allosteric activation of kinases in living cells. Nat Biotechnol. 2010;28:743-7.

\section{Submit your next manuscript to BioMed Central and take full advantage of:}

- Convenient online submission

- Thorough peer review

- No space constraints or color figure charges

- Immediate publication on acceptance

- Inclusion in PubMed, CAS, Scopus and Google Scholar

- Research which is freely available for redistribution 